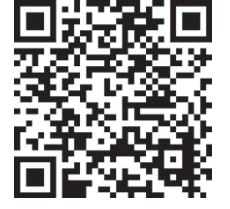

* Dirección General de Difusión e Investigación. Comisión Nacional de Arbitraje Médico.

Correspondencia: FMG, fmenesesg@conamed. gob.mx

Conflicto de intereses: Los autores declaran que no tienen.

Financiamiento: Ninguno Citar como: Carrasco ZD, Lezana FMA, Meneses GF. Un mensaje de reconocimiento y apoyo a los profesionales de la salud mexicanos. Rev CONAMED. 2020;28(1): 2. doi: $10.35366 / 92888$

Recibido: 21/04/2020. Aceptado: 21/04/2020.

\section{Un mensaje de reconocimiento y apoyo a los profesionales de la salud mexicanos}

\author{
A message of recognition and support for Mexican health professionals \\ Daniela Carrasco Zúñiga,* Miguel Ángel Lezana Fernández,* Fernando Meneses-Conzález*
}

En estos tiempos en los que nuestro país se encuentra en una emergencia sanitaria por causa de fuerza mayor, debido a la presencia y transmisión del virus SARS-CoV-2, la Revista CONAMED continúa con su labor de difusión de información relacionada con seguridad del paciente, calidad de la atención y derecho sanitario.

El personal de salud en nuestro país (enfermería, medicina, odontología, farmacéuticos, químicos laboratoristas, trabajo social, administrativos, auxiliares de limpieza y mantenimiento, vigilancia y demás personal involucrado en el cuidado de la salud) está mostrando su valor, entereza y capacidades técnicas en la primera línea de atención y contención de casos que acuden a los servicios de salud. Reciban nuestro más amplio reconocimiento y apoyo a la actividad que realizan.

Hemos visto cómo el equipo de salud ha sido agredido e insultado por un mínimo sector de la población, lo que reprobamos enérgicamente y, por el contrario, nos solidarizamos con nuestro personal de salud.

La gravedad de la infección por SARS-CoV-2 es mayor en quienes tienen alguna comorbilidad, como puede ser diabetes mellitus, hipertensión arterial o pulmonar, insuficiencia renal u otra enfermedad crónica no transmisible; por esto, es necesario que el primer nivel de atención participe activamente en el control de los pacientes que tienen estos padecimientos.

Durante estos tiempos difíciles para la salud de los mexicanos, nos sumamos al llamado para realizar las acciones de salud pública que apoyen, faciliten y contribuyan a reducir los daños en salud provocados por COVID-19.

Exhortamos a nuestros lectores a sumarse a dichas acciones de salud pública y solidarizarnos con los profesionales de la salud que trabajan, día a día, en las diversas unidades médicas para la atención oportuna y de calidad de los enfermos de COVID-19.

Saludo afectuoso, sincero y solidario para todos ellos. 